\title{
Defining Asbestos: Differences between the Built and Natural Environments
}

\author{
Mickey E. Gunterab
}

\begin{abstract}
Asbestos - while most think they know what this material is, few understand the current issues surrounding it. Few would also realize that asbestos is the form of a mineral, and even fewer would know that there are different types of asbestos, that not only had different industrial applications, but pose differing health risks when inhaled. Asbestos was in wide-spread use mid-last century in many consumer products, and no doubt saved thousands of lives, but by the latter part of last century concerns over its health risk caused its use to wane, to the point it was removed from many buildings. So in many ways the asbestos story was coming to an end in the 1990s, but two events in the USA - the vermiculite ore produced from Libby, Montana which contained amphibole asbestos and was used in a million homes in the USA as attic insulation and the concern for exposure to asbestos occurring in its natural setting in El Dorado Hills, California led to an increased concern of the potential for low-level environmental exposure to asbestos to the general public. The current dilemma we find ourselves in, especially in the USA, deals with the relationships between our knowledge of handling asbestos and an understanding of its risk potential in the built environment versus the natural environment. And one perfect metaphor for this is the term used by many non-geologists to differentiate asbestos in the built vs natural environment - 'naturally occurring asbestos'. Clearly a misstatement, but only one of many we must deal with as we struggle to understand the risk to humans of natural occurrences of asbestos. This paper will try and address some of these issues centering around those occurring in the USA.
\end{abstract}

Keywords: Amphibole · Asbestiform · Asbestos · Chrysotile · Diffraction · Microscopy $\cdot$ Serpentine

\section{Introduction}

It may come as a surprise to most chemists that asbestos is not well defined, and, based on my experience, it also comes as a surprise to many that asbestos is a naturally occurring material. Mineralogy - my field - studies minerals, which are defined briefly as 'naturally occurring solids possessing a repeating array of atoms and a certain chemical composition'. [1] To a chemist, a mineralogist might be called a solid-state inorganic chemist who studies naturally occurring compounds. Note the repeat-

${ }^{*}$ Correspondence: Prof. Dr. M. E. Gunterab

Tel.: + 012088856015

Fax: + 012088855724

E-mail: mgunter@uidaho.edu

${ }^{a}$ Geological Sciences

University of Idaho

Moscow, Idaho 83844 USA

bMarsh Professor-at-Large

University of Vermont

Burlington, Vermont 05405 USA

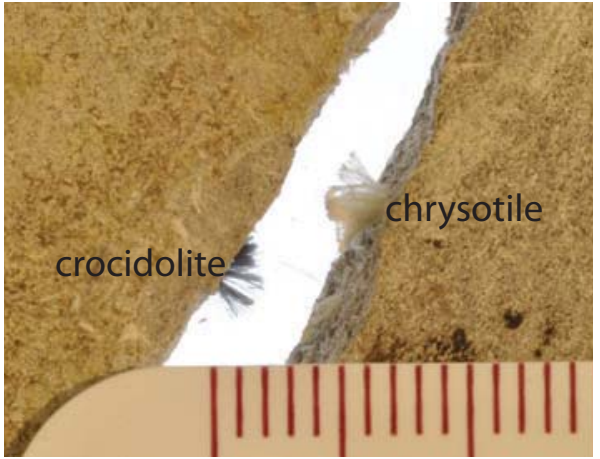

Fig. 1. Photographs of common asbestoscontaining cement building products: roofing material from Italy (left) and house siding from the USA (right). (The scale is in $\mathrm{mm}$.)

ing theme of 'naturally occurring'. Thus because all asbestos are minerals that, by definition occur naturally, it is natural that mineralogists study asbestos. However, because asbestos also had many industrial applications, which have led to negative health effects among those who mined, milled, produced, and used asbestos containing products, many other disciplines are involved in the study of asbestos. ${ }^{[2-4]}$ Over the years asbestos has found use in many industrial products world-wide, and Fig. 1 shows just one of the more common uses - as a binder in cement products - so it is clear that many in society would be exposed to these products during their installation and subsequent removal.

\section{Defining Asbestos}

Asbestos is more of a commercial than scientific term. And like many terms that are used by different disciplines, the meaning is often different between the groups. In the commercial realm asbestos is referred to as a group of six fibrous minerals that could be mined and used in several industrial applications. Table 1 lists these six minerals. Note the first three have special names when they occur as asbestos while the last three do not. Also note five of the six are amphiboles. Intertwined with the commercial definition is the regulatory one, which basically regulates the six previously mentioned minerals. Thus compositionally, the asbestos minerals are regulated based on mineral species name, as defined by the mineralogical community.

From a mineralogical perspective the asbestos minerals all exhibit the asbestiform habit or morphology, and this is what makes them unique. Asbestiform has a straight-forward definition, meaning 'to be separated lengthwise into fibers'. However, the crux of this issue deals with the definition of a fiber. From a regulatory perspective, a fiber is defined based on its so-called aspect ratio. To add to the confusion, different aspect ratios are often used depending on the type of microscope used to examine the particle. For example, a particle is counted as a fiber in the polarized light microscope (PLM) if it is three times 
Table 1. The six regulated asbestos mineral species and ideal end-member formulas ${ }^{[1]}$

$\begin{array}{lll}\text { Mineral name } & \text { Name when asbestiform } & \text { Chemical formula } \\ \text { serpentine } & \text { chrysotile } & \mathrm{Mg}_{3} \mathrm{Si}_{2} \mathrm{O}_{5}(\mathrm{OH})_{4} \\ \text { riebeckite } & \text { crocidolite } & \mathrm{Na}_{2} \mathrm{Fe}^{2+}{ }_{3} \mathrm{Fe}_{2}^{3+} \mathrm{Si}_{8} \mathrm{O}_{22}(\mathrm{OH})_{2} \\ \text { grunerite } & \text { amosite } & \mathrm{Fe}_{7} \mathrm{Si}_{8} \mathrm{O}_{22}(\mathrm{OH})_{2} \\ \text { anthophyllite } & \text { anthophyllite asbestos } & \mathrm{Mg}_{7} \mathrm{Si}_{8} \mathrm{O}_{22}(\mathrm{OH})_{2} \\ \text { tremolite } & \text { tremolite asbestos } & \mathrm{Ca}_{2} \mathrm{Mg}_{5} \mathrm{Si}_{8} \mathrm{O}_{22}(\mathrm{OH})_{2} \\ \text { actinolite } & \text { actinolite asbestos } & \mathrm{Ca}_{2}(\mathrm{Mg}, \mathrm{Fe})_{5} \mathrm{Si}_{8} \mathrm{O}_{22}(\mathrm{OH})_{2}\end{array}$

longer than it is wide (i.e. an aspect ratio greater than 3 to 1 ; for reference see: $h t t p: / /$ edocket.access.gpo.gov/cfr_2009/julqtr/ pdf/40cfr763EAppE.pdf), but would need a 5 to 1 aspect ratio to be counted as a fiber if observed in a transmission electron microscope (TEM) (for reference see: $h t t p: / /$ edocket.access.gpo.gov/cfr_2009/julqtr/ pdf/40cfr763EAppA.pdf). To a mineralogist, a fiber would need to exhibit a certain set of physical properties (i.e. be curved and flexible). Thus, asbestos has both a compositional definition, which is more or less well defined, as well as a morphological one, which varies between disciplines.

Fig. 2 shows examples of two asbestiform and one non-asbestiform amphibole. The dark-colored euhedral sample in the center of Fig. 2A is tremolite, while the two fibrous samples are tremolite asbestos (the lighter one) and crocidolite (the darker one). Note the asbestiform habit: separating lengthwise into fibers and the fibers exhibit curvature. Departing slightly from asbestos nomenclature, minerals also have a property termed cleavage. Cleavage results from minerals exhibiting weak planes through their structure, and when a force is applied they break along those weak planes. Thus, the only method to determine with certainty if a mineral has cleavage, is to break it. Likewise, the only method to determine with certainty if a mineral exhibits asbestiform morphology is to apply a force and to determine if the particle separates lengthwise into fibers. Fig. 2B shows a piece of tremolite (the same as in Fig. 2A) before (left) and after (right) a force has been applied to it. Note the sample is broken into smaller pieces both lengthwise and perpendicular to its elongation. Likewise, in Fig. 2C a small piece of the tremolite asbestos (the same as in Fig. 2A) has had a force applied to

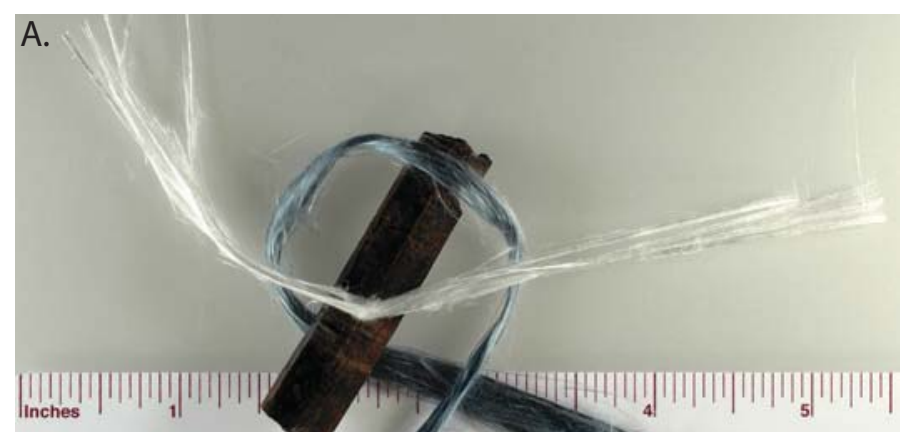

Virginia Tech Dopartme. Geoscienc B.

B.

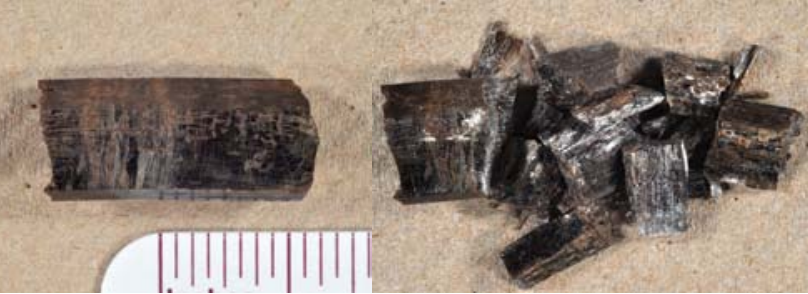

C.

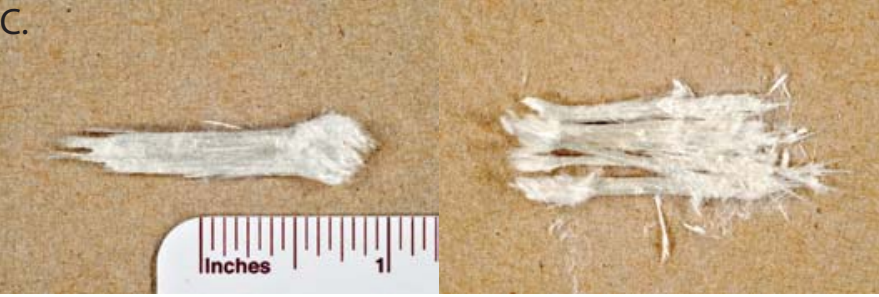

Fig. 2. Hand-sample samples of asbestiform minerals. A. The white fibrous sample is tremolite asbestos and blue crocidolite, while the dark colored euhedral crystal is nonasbestiform tremolite. ${ }^{[3]}$ B. A close up of a piece of the euhedral sample from $A$ before (left) and after (right) being broken. C. A close up of a piece of the tremolite asbestos sample from A before (left) and after (right) being broken.

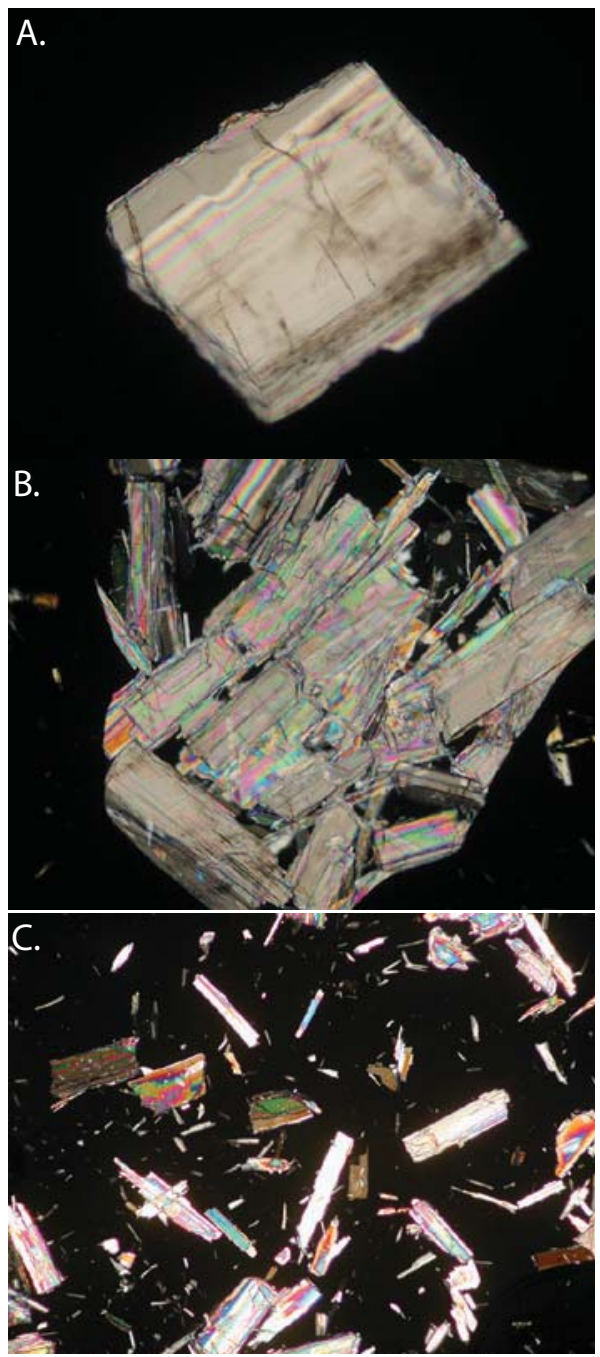

Fig. 3. A series of photomicrographs of a tremolite grain (FOV $=2.5 \mathrm{~mm}$ ). Shown in $A$ is the original single crystal, then in B the crystal has been broken and further broken in $\mathrm{C}$.

it and shows lengthwise separation into fibers, confirming that it is an asbestiform variety of amphibole. As particle size decreases beyond being visible to the human eye, microscopes are used to determine the morphology of the particles. Fig. 3 shows PLM photographs of a non-asbestiform amphibole particle. Fig. 3A shows the single crystal; note that it would not meet the counting criteria (i.e. have an aspect ratio greater than 3 to 1 ) to be considered a fiber. In Fig. 3B the particle from Fig. $3 \mathrm{~A}$ has been crushed, now many of these particles exhibit aspect ratios to be considered fibers and thus counted as asbestos by the regulatory definitions, but clearly this is not asbestos by the mineralogical definition. Fig. 3C shows further crushing of the particle yielding many smaller fragments, which meet the counting criteria to be fibers, but are still not asbestos. In general, the term 'cleavage fragment' is applied to these smaller particles derived from the crushing of larger ones. And there is debate whether cleavage fragments present any 


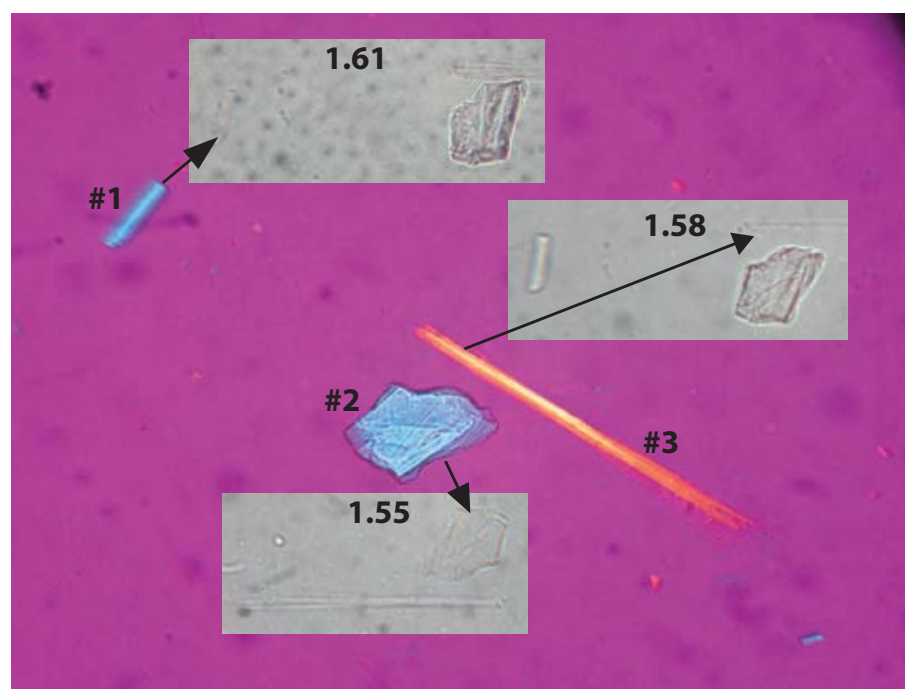

Fig. 4. A

photomicrograph of three particles exhibiting differing morphology (FOV = $0.5 \mathrm{~mm}$ ): particle 1 is elongated, particle 2 platy, and particle 3 asbestiform. To aid in particle identification, its refractive index can be matched to that of a liquid as shown in the numbered inserts: using this information, particle 1 is tremolite, particle 2 serpentine, and particle 3 talc. health issues, with current research tending to indicate they do not. ${ }^{[3,5-7]}$ Regardless, there is an on-going debate about the definition of asbestos that exists between the private sector and government agencies in the USA. ${ }^{[8,9]}$

Another issue deals with the fact that in mining operations often many different minerals are encountered. For example, Fig. 4 shows three distinct mineral morphologies and in turn three separate minerals photographed in the PLM. Particle 1 has an elongated morphology and would meet the counting criteria for asbestos, but is not an asbestos particle. Particle 2 is a platy particle and thus not asbestos, while Particle 3 exhibits the asbestiform habit, but is a particle of talc, thus it is not asbestos. At this point you can see the need to correctly identify the mineral as well as to determine the composition and structure of the mineral to ascertain if it is asbestos or not. One method to do this is to match the refractive index of the mineral to the refractive index of a liquid in which it has been immersed. There are three inserts shown in Fig. 4, note how in each one the minerals appear differently, becoming less visible as their refractive index approaches that of the liquid (which is given as a number in the inset). Interestingly, particle 1 is tremolite and particle 2 is a serpentine group mineral, both of which, if occurring in the asbestiform habit, would be regulated, whereas talc, particle 3 which commonly occurs in a platy habit, but in these samples occurs in an asbestiform habit, is not regulated as asbestos even though it occurs here in an asbestiform habit.

For better characterization of the morphology of smaller particles, often electron microscopes are used. Also, electron microscopes can be equipped with an energy dispersive spectrometer (EDS), which will provide compositional data on individual particles. Fig. 5A shows the asbestos min- eral chrysotile at low (left) and high (right) magnification, clearly showing these particles are asbestiform. Interestingly, this mineral has the same composition as particle 2 in Fig. 4, which was platy. At the bottom of Fig. 5A is the EDS pattern showing the composition of the mineral, which aids in their identification. However, care must be taken on identifying minerals based solely on their composition without prior knowledge of what minerals might occur in the sample. ${ }^{[1]}$

\subsection{The Built Environment}

Many have forgotten why asbestos was first used. One of the first uses for asbestos was to build fireproof materials. Before asbestos was used as a fireproofing material many people needlessly lost their lives in building fires. ${ }^{[10]}$ Asbestos is also used as a construction material especially in cement products (Fig. 1). In these types of uses the types of asbestos used were easily distinguished from their non-asbestos analogues because they were true fibers (Fig. 1 and $2 \mathrm{C})$. Thus, the commercially used asbestos products were derived from asbestiform minerals.

As concerns for asbestos arose in the 1970s and 1980s, its production decreased and asbestos-containing products were often removed from buildings. During these removal processes it became necessary to monitor the asbestos content of the air to insure worker safety, as well as to ascertain that asbestos was completely removed from the building. The techniques that were developed obtained air samples that were in turn analyzed by phase contrast microscopy to determine the number of fibers per cubic centimeter of air. Fibers were counted if their aspect ratio was greater than 3 to 1 and their length greater than 5 microns (for reference see: $h t t p: / / w w w$. cdc.gov/niosh/docs/2003-154/pdfs/7400. $p d f)$. This method works well for the built

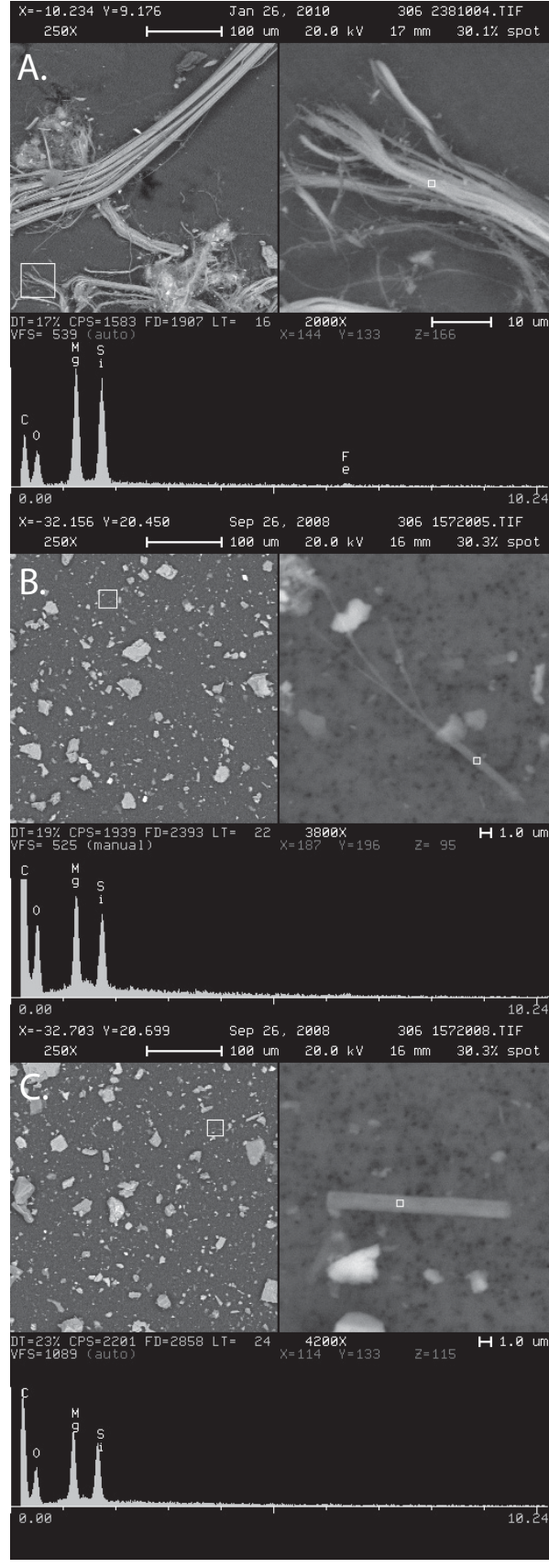

Fig. 5. SEM photographs (left image low magnification and right image high magnification) of serpentine group minerals with associated EDS data: chrysotile asbestos standard (A), chrysotile asbestos found in gravel in Vermont, USA (B), and a nonasbestiform serpentine particle found at the same location (C).

environment, but as will be seen, suffers severe limitations in the natural environment because many mineral particles occur in the elongated habit. Also, many of the same groups with extensive experience in the built environment (e.g. industrial hygienists, construction engineers, toxicologists), found themselves in a position to aid in the identification of asbestos in the natural environment, and used many of the techniques and tools developed for the built environment. 


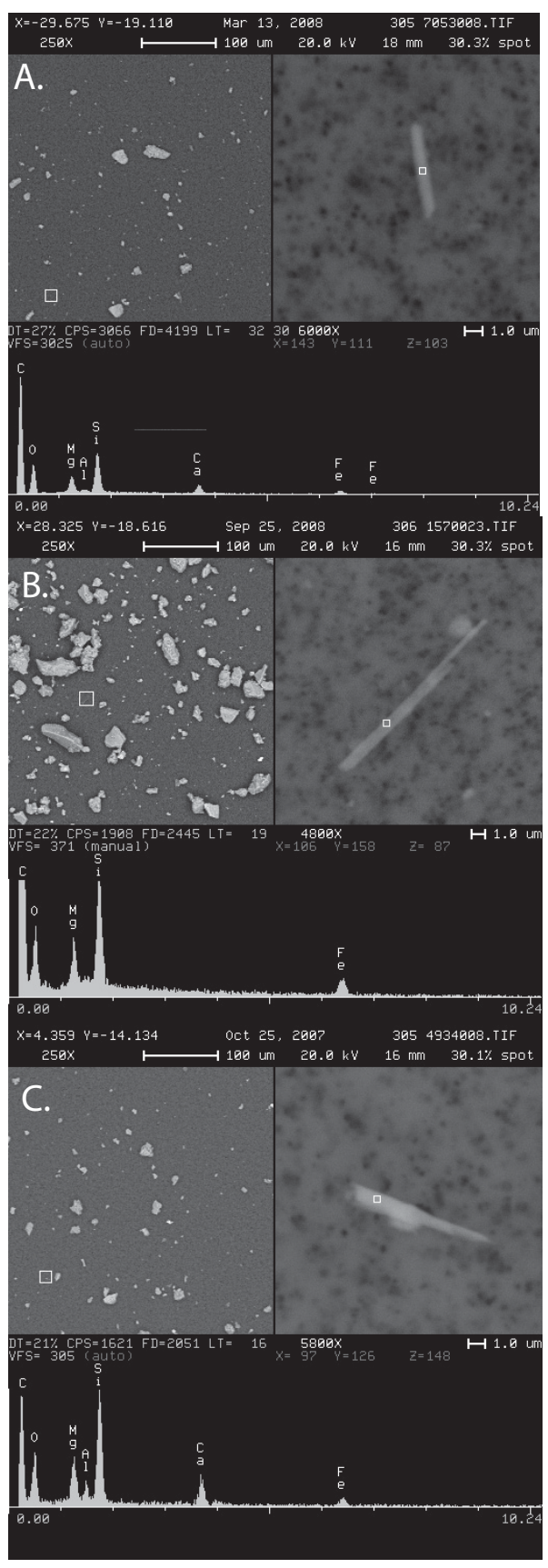

Fig. 6. Three SEM photographs, with associated EDS data, of amphiboles found in soils in Washington DC, USA (A), southern Illinois, USA (B), and western Montana, USA (C). Based on EDS data particles A and $B$ would be tremolite / actinolite and $C$ anthophyllite / grunerite.

\subsection{The Natural Environment}

It should be clear that it is fairly straightforward to distinguish asbestiform from non-asbestiform minerals at the hand-sample scale (Fig. 2), or when they have been used in commercial products (Fig. 1). However, moving to the natural environment the situation becomes much more complicated, especially when applying rules made for the built environment. Fig. 5B and $\mathrm{C}$ shows an example of this. These particles were removed from gravel in Vermont, USA. Fig. 5B is a chrysotile

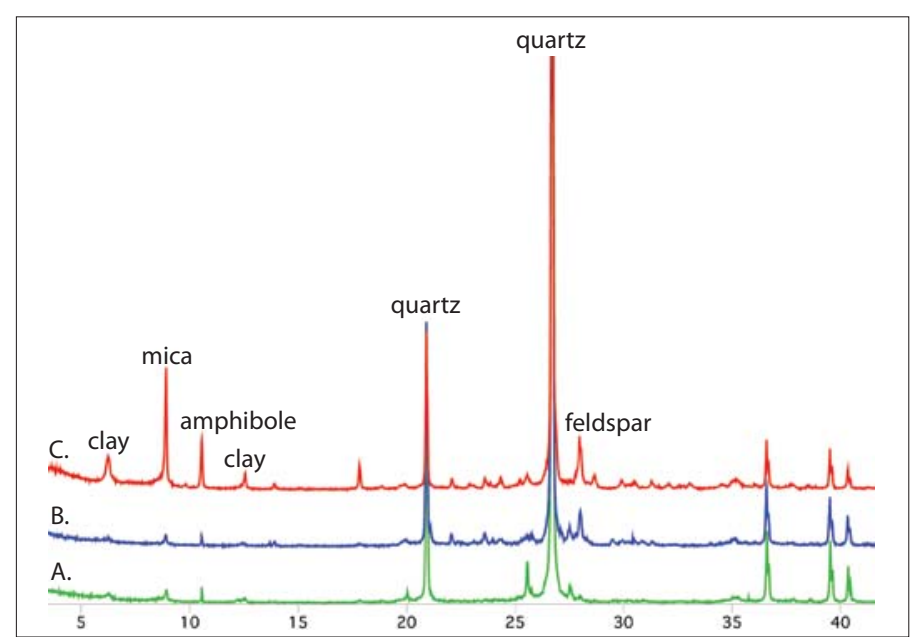

Fig. 7. Powder XRD pattern of three soils with major peaks labeled. These samples correspond to those in Fig. 6. asbestos particle clearly showing fiber splitting and curvature, while Fig. 5C shows a non-asbestiform serpentine group mineral. Regardless, Fig. 5C would be counted as an asbestos particle based on regulatory criteria. The situation becomes even more complicated when looking at amphibole minerals as they are much more abundant in the natural environment than serpentine group minerals, with amphiboles composing approximately $5 \%$ of the Earth's crust. ${ }^{[1]}$ For example, Fig. 6 shows three SEM photographs of non-asbestiform amphiboles that would all meet the counting criteria as a fiber. These samples were collected in eastern, mid-western, and western portions of the United States. In fact, our on-going work shows amphiboles occurring at the percent or higher level in many soils throughout the United States, and probably world, ${ }^{[11]}$ and our past work shows most non-asbestiform amphiboles would meet the counting criteria to be considered fibers. ${ }^{[12]}$ Interestingly, from a regulatory perspective, if a product contains above one percent asbestos some remedial action must be taken. This would imply that most soils and many rocks in the world would be contaminated.

As mentioned previously, mineral identification is based both on composition and structure, with structure of minerals routinely determined by some type of diffraction method. Fig. 7 shows a series of powder X-ray diffraction (XRD) patterns of three soil samples from the USA. These three soil samples are the same as the soil samples from which the amphiboles in Fig. 6 were obtained. Minerals are identified by this method by matching their known diffraction patterns to the observed peaks; in Fig. 7 several of the major peaks are labeled. As would be expected quartz and feldspars occur in all these samples because they are the two most common minerals in the earth's crust. Also, note amphiboles occur in all three of these samples. Methods have been developed to determine the amount of a potentially asbestiform minerals in a multi-mineral mix (i.e. a soil), ${ }^{[13]}$ and in this case these samples contain between 2 and $7 \%$ amphibole. While these amphiboles are probably not asbestiform, they would contain amphiboles that would meet the counting criteria to be considered a fiber (Fig. 6), and these soils would be considered contaminated based on current regulations in the USA.

\section{NOA - Natural Occurrences of Asbestos}

Over the last decade a concern has arisen to asbestos exposure in the natural environment, and the scientifically incorrect term 'naturally occurring asbestos' coined along with the acronym NOA. El Dorado Hills, California USA has been at the focal point of this issue. ${ }^{[3,14]}$ The issue arose because a homeowner discovered tremolite asbestos during a construction project in the soil. Government regulators became involved and the issue was also reported in the press, with the rationale that residents of the community could be at risk. Gunter ${ }^{[15]}$ discussed the origin of the term NOA and that its original meaning appeared to be natural occurrences of asbestos, which is more scientifically correct than the term naturally occurring asbestos. A portion of his argument was that it should be clear to the public that asbestos does occur in nature and if regulatory definitions of amphiboles were used rather than mineralogical ones, asbestos would be ubiquitous in soils and rocks in the world. There have been several studies on human exposure to NOA yielding somewhat different results. Pan et al.[16] found an increased risk based on an individual's proximity to mafic and ultramafic rocks in central California, while de Grisogono and Mottanna ${ }^{[17]}$ and Hendrickx ${ }^{[18]}$ found no correlations to individuals in Italy and eastern Australia. However, on the south- 

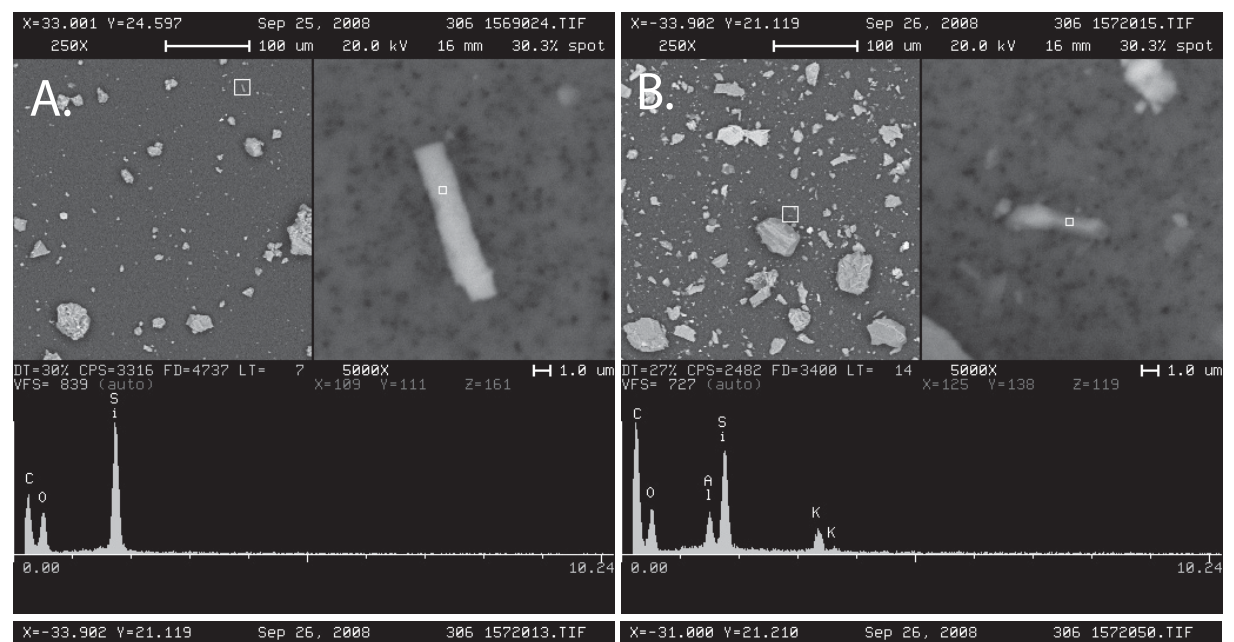

on the observation that because asbestos particles are elongated, possibly there is a health risk with any elongated mineral particle. As most mineralogy students learn early on, many minerals can occur in this elongated habit. For instance, Figs 8 and 9 show SEM photographs of elongate mineral particles found in soils scattered throughout the USA. In Fig. 8, these elongate minerals are common silicate rock-forming minerals such as feldspars, quartz, and sheet silicates. Fig. 9 shows non-silicate elongate mineral particles. It is worth noting that while it is indeed true that asbestos particles are elongated, it is still unclear what the exact mechanism of disease induction
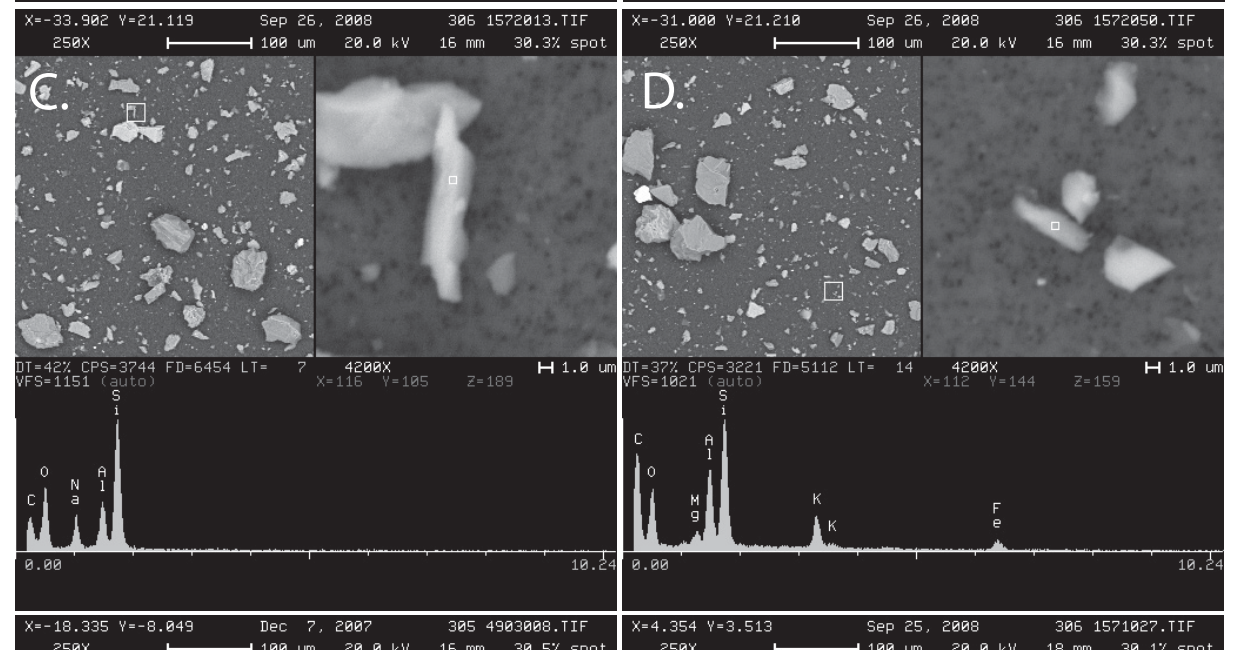
for asbestos is. We do know that there is a significance difference in the health impact of chrysotile and amphibole asbestos with the latter being more harmful.[26] One explanation for this difference is the retention rate of different asbestos minerals in the human lung. [27] Workers have been exposed to many minerals and to date there appears to be no negative health effects from inhalation of, for example, calcite, while there is from quartz - which commonly occurs in a non-fibrous habit. ${ }^{[28]}$ No doubt the morphology of the particle is important, but also the biodurability is equally important as would be exemplified by the highly soluble nature of calcite in the human lung as compared to the insolubility of quartz. ${ }^{[29]}$
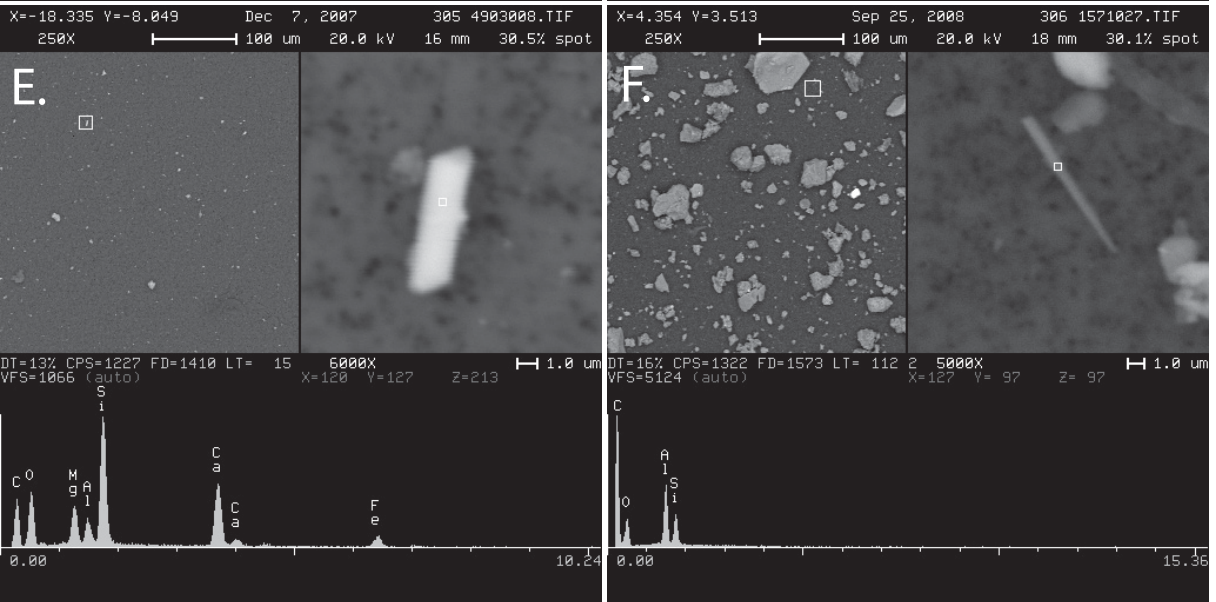

Fig. 8. SEM photos and associated EDS data for six common rock-forming silicate minerals found in soil samples showing an elongated habit: quartz (A), orthoclase (B), albite (C), mica (D), pryoxene $(E)$, and kaolinite or sillimanite $(F)$.

ern flank of Mt. Etna in Sicily, Burragato et al. ${ }^{[19]}$ document asbestos-related diseases in residents living near a quarry containing amphibole asbestos.

Concerns have spread from California to many other locations in the USA where asbestos was known to occur. These occurrences are associated with certain rock types that commonly occur in the mountainous regions in the USA, and world. Van Gosen has published a series of maps locating these types of deposits in the United States. ${ }^{[20-25]}$ Our ongoing work shows many soils in the USA, regardless of their location, contain amphiboles. ${ }^{[11]}$ This is clearly a public policy issue as discussed in Lee et al. ${ }^{[25]}$

\section{Elongate Mineral Particles}

In a similar manner to NOA, concerns have also spread from asbestos exposure to any mineral that might possess an aspect ratio greater than 3 to 1 . In fact, this class of particles has recently been given the name 'elongate mineral particles' by a US agency. ${ }^{[9]}$ Their rational was based

\section{The Libby, Montana Experience}

In many ways a reinterest in asbestos occurred in 1999 when issues surrounding the former vermiculite mine near Libby, Montana were reported in the popular press in the USA. ${ }^{[3,30,31]}$ Unfortunately the vermiculite ore contained trace amounts of amphibole asbestos, and the workers exposed to this material had increased rates of asbestos-related respiratory diseases. Concerns spread from the workers, to their families, and residents of Libby, Montana, and also to the residents of approximately one million homes in the USA that have used this material as attic insulation. Many asbestos-related issues have developed over the last decade in Libby. One issue dealt with the compositional definition of asbestos. It turns out the majority of the amphiboles in the deposit are the nonregulated amphibole species winchite and richterite. This posed an interesting legal question in that even though the mineral was not regulated, were laws still broken in exposing workers to the material? Regardless, this issue clearly points to the need for thorough characterization of these minerals of environmental concern.

An ongoing issue is possible soil contamination in the town of Libby from the former mine and mill. In our work exam- 

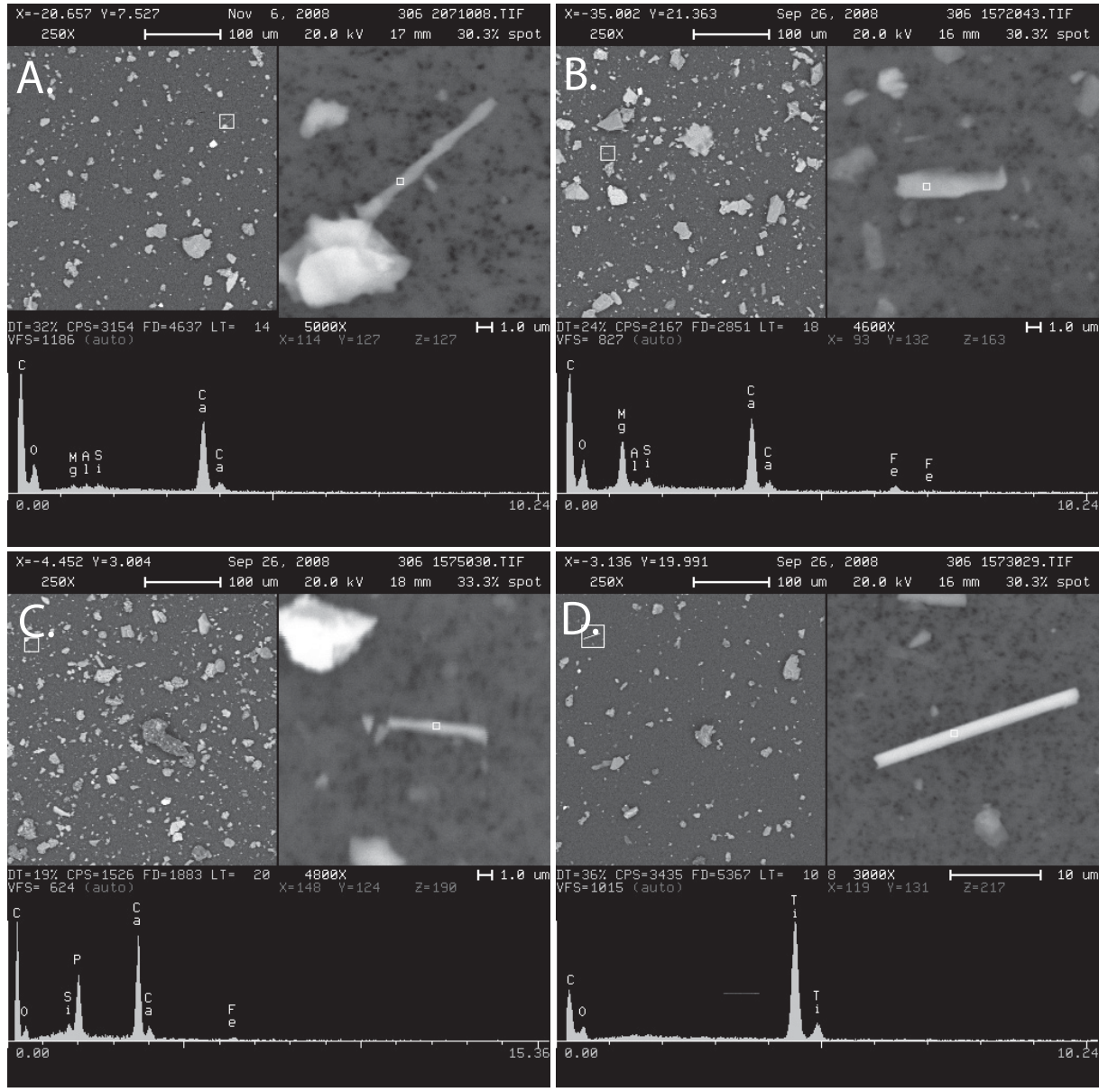

Fig. 9. SEM photos and associated EDS data for four non-silicate minerals found in soil samples showing an elongated habit: calcite (A), dolomite (B), apatite (C), and rutile (D).

ining soils in Libby, as expected we found amphiboles from the vermiculite deposit, but we also found amphiboles not from the vermiculite deposit. [31] This would be another example of amphiboles occurring in their natural setting, versus contamination of amphiboles from a mine. It is significant in this case to determine what group would be responsible for remediation if the soils contained natural occurrences of asbestos versus asbestos from a local mine.

As pointed out by Gunter and Sanchez ${ }^{[31]}$ the majority of the amphiboles found in the soils in Libby does not originate from the local vermiculite mine, but occur as amphiboles in their natural setting. Thus soils may be deemed to be contaminated when they contain natural occurrences of nonasbestiform amphiboles simply because the amphiboles meet the counting criteria to be considered a fiber. Ironically some houses in Libby are covered with chrysotile-containing products as shown in Fig. 1, which are left on the structures after the soils have been remediated.

\section{Conclusion}

It should be clear that when asbestos was used in the built environment, one could distinguish it from other products used in that setting. However, when one moves to the natural environment, it can be very difficult to distinguish, or define, asbestos. Unfortunately this issue appears to be gaining more attention, and the only way it will get resolved is for all those involved in asbestos issues to work together and try and understand the true risk to society in regards to exposure to these air and soil of our planet. Common sense might lead us to conclude this risk is low, and that if we chose to regulate these products society would find it hard to cultivate soils or mine rock of any type to satisfy the reliance of our modern society on natural resources.

\section{Acknowledgement}

I would like to thank Dr. Prof. Thomas Armbruster for inviting me to write this article and the assistance given by two reviewers.

Received: August 17, 2010

[1] M. D. Dyar, M. E. Gunter, 'Mineralogy and Optical Mineralogy', Mineralogical Society of America, Chantilly, Virginia, 2008, 708 pp.

[2] G. D. Guthrie, B. T. Mossman, Reviews in Mineralogy, Mineralogical Society of America, 1993, vol. 28. natural materials distributed thought the
[3] M. E. Gunter, E. Belluso, A. Mottana, in 'Amphiboles: Crystal Chemistry, Occurrences, and Health Concerns', Reviews in Mineralogy and Geochemistry 2007, 67, 453.

[4] N. Sahai, M. A. A. Schoonen, Reviews in Mineralogy and Geochemistry, Mineralogical Society of America, 2006, vol. 64

[5] J. Addison, E. E. McConnell, J. Regul. Toxicol. Pharmacol. 2008, 52, S187.

[6] J. F. Gamble, G. W. Gibbs, J. Regul. Toxicol. Pharmacol. 2008, 52, S154.

[7] B. T. Mossman, J. Regul. Toxicol. Pharmacol. 2008, $52, \mathrm{~S} 200$.

[8] R. E. Glenn, R. J. Lee, L. M. Jasterm, K. L. Bunker, D. R. Van Orden, B. R. Strohmeier, Chem. Regul. Rep. 2008, 32, 22.

[9] NIOSH, 'Asbestos fibers and other elongate mineral particles: State of science and roadmap for research', 2010, version 4.

[10] R. P. Maines, 'Asbestos and Fire: Technological trade-offs and the body of risk', Rutgers University Press, New Brunswick, New Jersey, USA.

[11] B. D. Thompson, M. E. Gunter, M. A. Wilson, 'Using the USDA-NRCS soil survey database to evaluate amphibole content of soils in the United States', Geological Society of America Abstracts with Programs, 2009.

[12] B. M. Brown, M. E. Gunter, The Microscope 2003, 51, 121.

[13] M. S. Sanchez, M. E. Gunter, C. L. Lopano, 'Using powder X-ray diffraction to screen for asbestos minerals occurring in their natural settings', $14^{\text {th }}$ International Clay Conference, Castellaneta, Italy, 2009.

[14] G. P. Meeker, H. A. Lowers, G. A. Swayze, B. S. Van Gosen, S. J. Sutley, I. K. Brownfield, USGS Open File Report 2006-1362.

[15] M. E. Gunter, 'Asbestos sans mineralogy', Elements 2009, 141.

[16] X. Pan, H. W. Day, W. Wang, L. A. Beckett, M. B. Shenker, J. Respir. Crit. Care Med. 2005, $172,1019$.

[17] F. M. de Grisogono, A. Mottana, Rend. Fis. Acc. Lincei 2009, DOI 10.1007/s 12210-009-0044x.

[18] M. Hendrickx, Environ. Geol. 2008, DOI 10.1007/s00254-008-1370-5.

[19] V. Burragato, P. Comba, V. Baiocchi, D. M Palladino, S. Simei, A. Gianfagna, L. Paoletti, R. Pasetto, Environ. Geol. 2005, 47, 855.

[20] B. S. Van Gosen, USGS Open File Report 20051189 , version 2.0.

[21] B. S. Van Gosen, USGS Open File Report 20061211 , version 1.0

[22] B. S. Van Gosen, USGS Open File Report $2007-$ 1182, version 1.0 .

[23] B. S. Van Gosen, USGS Open File Report 20081095, version 1.0

[24] B. S. Van Gosen, USGS Open File Report 20101041 , version 1.0

[25] R. J. Lee, K. L. Strohmeier, K. L. Bunker, K.L., D. R. Van Orden, J. Haz. Mater. 2008, 153, 1.

[26] M. E. Gunter, J. Geol. Edu. 1994, 42, 17.

[27] S. A. Wood, A. E. Taunton, C. Normand, M. E. Gunter, Inhal. Toxicol. 2006, 18, 975.

[28] M. E. Gunter, J. Geosci. Edu. 1999, 47, 341.

[29] A. E. Taunton, M. E. Gunter, G. K. Druschel, S. A. Wood, 'Geochemistry in the lung: Reactionpath modeling and experimental examination of rock-forming minerals under physiologic conditions', Amer. Mineral. 2010, in press.

[30] B. R. Bandli, M. E. Gunter, Inhal. Toxicol. 2006, $18,949$.

[31] M. E. Gunter, M.S. Sanchez, Amer. Mineral. 2009, 94, 837. 